\title{
Impact of the Iron Gates on the Sediments with an Emphasis on the Area of the Future Belene Nuclear Power Plant
}

\author{
Tzviatka Karagiozova and Plamen Ninov \\ National Institute of Meteorology and Hydrology, Sofia 1784, Bulgaria
}

\begin{abstract}
The present investigation has been fulfilled with a view to the future nuclear power station constriction near the Belene Island. Sediment loads and sediment transportation are important factors for the technical water supply of the nuclear station Belene. The paper deals with change of suspended sediment load at Bulgarian part of the Danube River downstream of the Iron Gates. Recent data on suspended sediment loads for the hydrometric gauge station at Svishtov have been collected, computed and presented. The results obtained discover the time variability of the sediment loads, climate change and the anthropogenic impact on the suspended sediments. The tendency of alteration and inter-annual variability of the suspended sediments are investigated and characteristics of average annual, monthly and maximal values are shown. In the material archive granulometric data are presented for this part of the Bulgarian stretch before the Iron Gates construction in the conditions of the natural sediment regime. There are statistical parameters of the studied characteristics of the river turbidity and discharge before and after the anthropogenic impact. The increase of the absolute minimal turbidity has been determined after the Iron Gate I as a result of activation of the bed processes and hydro-morphological changes.
\end{abstract}

Key words: Suspended sediment load, climate change impact, anthropogenic impact.

\section{Introduction}

The present investigation of the Danube sediment runoff has been fulfilled with a view to the nuclear power station constriction (Belene NPP (Nuclear Power Plant)) near the Belene Island in the frame of the next several years. The nuclear station platform is situated in the Svishtov-Belene lowland at $571 \mathrm{~km}$ on the bank of the Belene Branch of the Danube River in front of the Persin (Belene) Island - the biggest one in Low Danube.

The sediment runoff with its temporal and inter-annual variability has been investigated looking at the technical water supply of the future nuclear power station. According to the Belene NPP documentation the realization of the technical water supply is projected with a direct usage of the Danube

Corresponding author: Plamen Ninov, Ph.D., professor, research fields: hydrology, sediments. water from the Belene Branch.

The present study is based on the collected archive sediment runoff information of the NIMH (National Institute of Meteorology and Hydrology) using the hydrometric gauge station Svishtov located $10 \mathrm{~km}$ from the Belene Island. The hydrometric station is accepted as representative because of the small distance to the nuclear station platform and the lack of additional inflowing into this Danube Stretch. These factors predestine the homogeneity of the hydrologic conditions in the frame of the whole Danube Stretch between the constriction platform and the observation monitoring point.

\subsection{Sediment Monitoring and Treatment}

In Bulgaria, the main purpose of the suspended sediment monitoring is to determine the SSC (suspended Sediment concentration) $(\mathrm{mg} / \mathrm{L})$. The one liter $(1 \mathrm{~L})$ sampler is lowered from a vertical in the area 
along the Bulgarian bank using the depth-integral method.

The sediment discharge $(\mathrm{kg} / \mathrm{s})$ is calculated using the determined (in the Sediment Laboratory) sediment concentration and the daily water discharge on the sampling days. The collected integral sample is assessed as average turbidity in the cross section of the river. The sampling numbers depend on the hydrological regime of the river aiming the best fit to the hydrograph and especially the flood periods. A sediment rating curve (suspended sediment discharge/water discharge relationship) is applied to obtain the value of daily sediment discharge. The present scheme of sampling is applied to the gauging stations located along the Danube tributaries. Regarding the main Danube stream the sampling has a daily step and the determination of the turbidity, respectively the sediment discharges, is obtained by direct calculations missing the rating curves build up.

NIMH has a specialized laboratory for sediment treatment of the samples from the whole country. The laboratory analysis contains concentration measurement and particle size distribution analysis. The filtering method is used for the SSC measurements. The water samples are passed through a filter of a diameter of $2-3 \mu \mathrm{m}$ at the river stations and are submitted in the Laboratory of NIMH. After filtering, the filter is dried at $105{ }^{\circ} \mathrm{C}$ for $2 \mathrm{~h}$ and weighed. The method used in the laboratory is a quantitative analysis by weight. The sample is weighed by analytical balance with an error of $0.1 \mathrm{mg}$. Furthermore there is a special furnace for additional treatment of the samples and organic/mineral content determination.

\section{Suspended Load Time Series}

\subsection{Suspended Load Time Series}

At present the regular turbidity monitoring along the Bulgarian Danube Sector is located at three points: the towns Lom, Svishtov and Silistra. The registration of the measured data has begun since 1961 at Svishtov
Town and except a brief interruption in 2009 continues till nowadays.

The sediment runoff in Low Danube before 1970 is shaped as results of anthropogenic factors mainly in the Upper and Middle Stream-construction of impounding reservoir, power plant chains in the upper river stretches, river shortening/straightening (meander cut-off) to increase transport capacity, dredging for waterway transport and construction purposes and so on. The variability of the average sediment discharge at Svishtov Town for the period 1961-2008 (Fig. 1) shows a multi-annual tendency of diminishing presented by a function:

$$
R=1612.6-29.183 \times t,
$$

Where:

$R$ - sediment discharge $(\mathrm{kg} / \mathrm{s})$;

$t$-number of years.

According to the above equation sediment discharge diminishes at this gauging point each year with an average value of $R=920 \times 10^{3}$ tons.

In 1970 and 1983 consecutively, the barrages of Iron Gates I and II have been constructed. The Iron Gates Water Power and Navigation System consist of two reservoirs built on the Yugoslav-Romanian section of the Danube River. The upstream dam Iron Gates I, located at $943 \mathrm{~km}$ of the Danube River. The important characteristics of the reservoir are the variable heights of water level and extension of the backwater zone, depending on the inflow and the power-plant operation. The average volume of the reservoir is $2.1 \times 10^{9} \sim 3.5 \times$ $10^{9} \mathrm{~m}^{3}$ according to impoundment.

The downstream dam Iron Gates II is located at $862.8 \mathrm{~km}$ of the Danube River. This reservoir is a smaller part of the system. The main objective of its construction was the additional use of water power and improvement of navigation conditions.

The construction of Iron Gates I and II differentiates four sub-periods looking at the impacts on the sediment runoff along the Bulgarian Danube Sector and illustrated by Hydrometric Gage Station Svishtov data $(554.3 \mathrm{~km})$ : 
- 1961-1970: Lack of significant hydro-technical constructions in Low Danube;

- 1971-1983: Iron Gate I is in operation;

- 1984-1995: Iron Gate I and Iron Gate II are both in operation and severe droughts period in Balkan region;

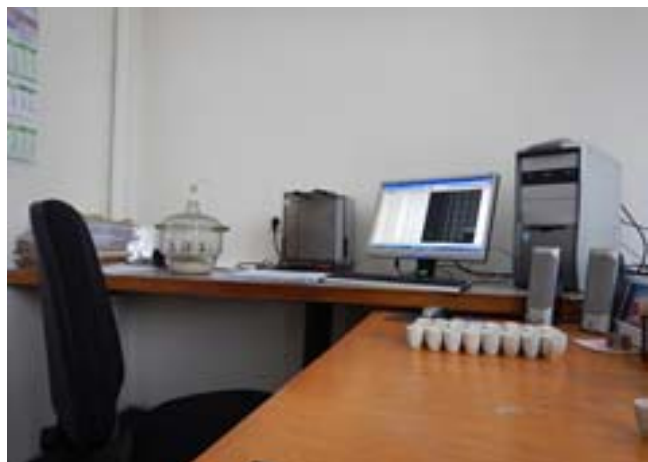

(a)
- 1996-2008: Period after the droughts period in Balkan region with wet years.

Fig. 2 demonstrated the alteration of average annual sediment discharge for the four sub-periods using the sediment runoff data for the Danube at Svishtov Hydrometric Station $(554.3 \mathrm{~km})$.

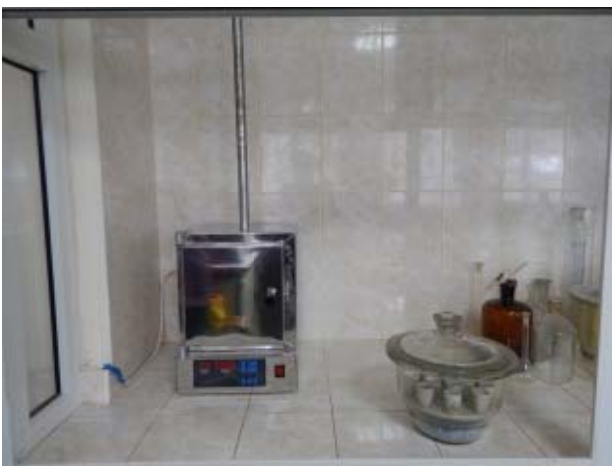

(b)

Photo (a) Electronic scale and sediment weight determination; (b) Furnace for organic/mineral content determination.

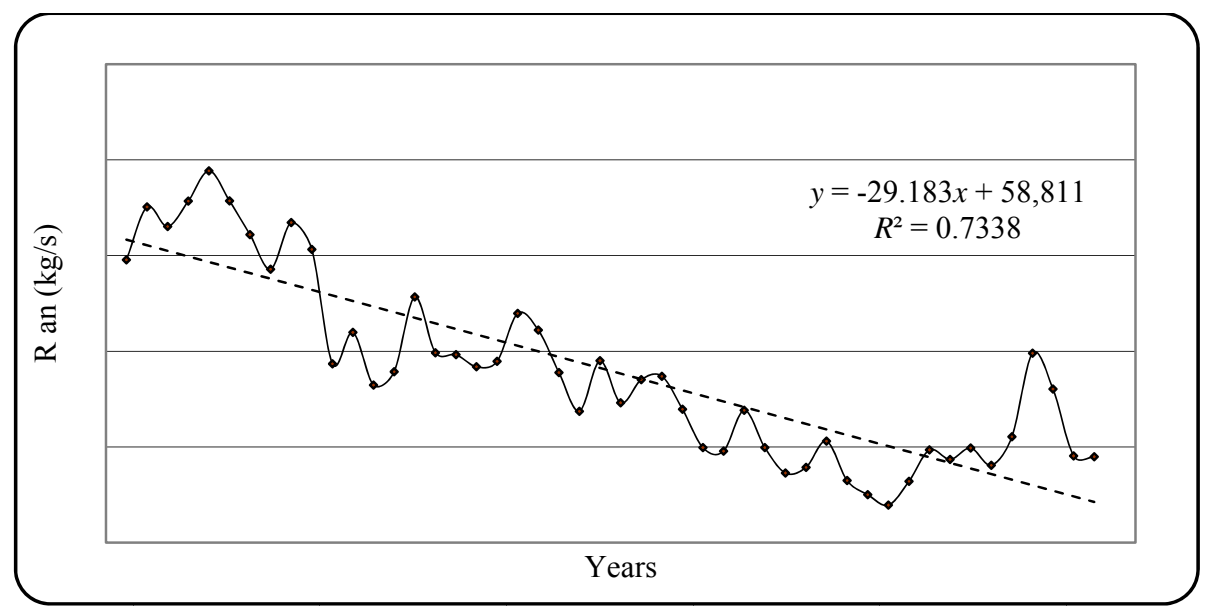

Fig. 1 The Danube River average annual sediment discharge variation at Svishtov Hydrometric Station (554.3 km).

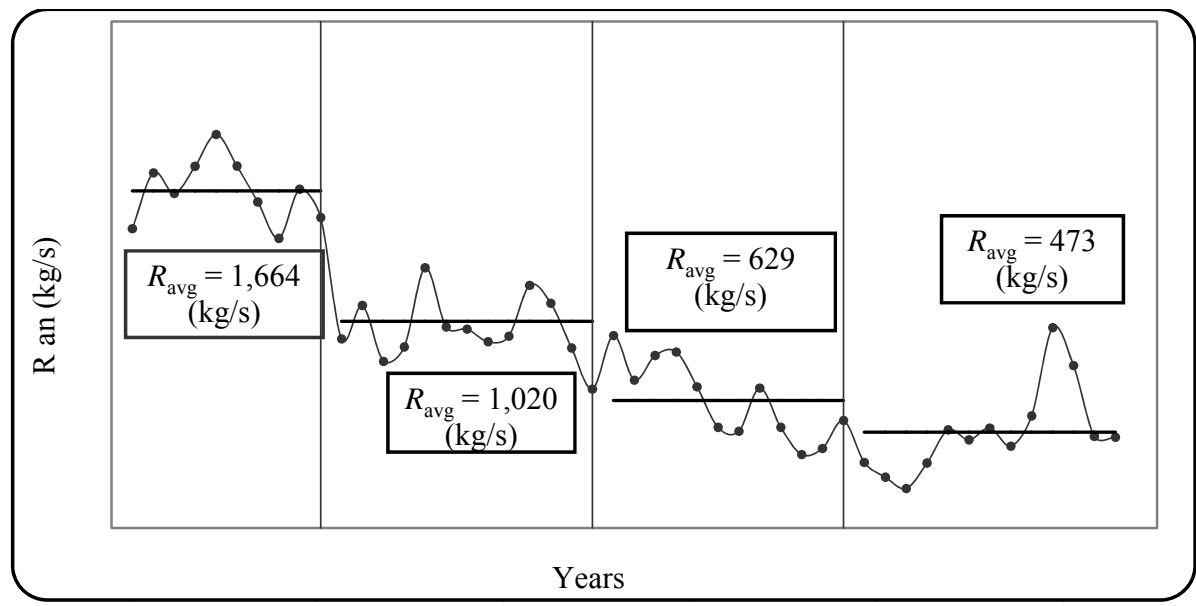

Fig. 2 Alteration of average annual sediment discharge for the four sub-periods at Svishtov Hydrometric Station $(554.3 \mathrm{~km})$. 
Table 1 Tendencies of alteration of the average annual sediment discharge $(\mathrm{kg} / \mathrm{s})$ at Svishtov Hydrometric Station.

\begin{tabular}{lllll}
\hline Period & $\begin{array}{l}R_{\text {annual }} \\
(\mathrm{kg} / \mathrm{s})\end{array}$ & $\begin{array}{l}\text { Duration } \\
(\text { year })\end{array}$ & $\begin{array}{l}R \\
\left(\times 10^{6} \mathrm{t} / \mathrm{an}\right)\end{array}$ & $\begin{array}{l}\text { Tendencies of alteration }(\mathrm{kg} / \mathrm{s}) \\
(\text { where } t \text { is time for years) }\end{array}$ \\
\hline $1961-1970$ & 1,664 & 10 & 52.48 & $R=1,726.9-11.44 \times t$ \\
$1971-1983$ & 1,020 & 13 & 32.17 & $R=1,028.1-6.71 \times t$ \\
$1984-1995$ & 629 & 12 & 19.84 & $R=923.44-45.35 \times t$ \\
$1996-2008$ & 473 & 12 & 14.92 & $R=230.85+34.60 \times t$ \\
\hline
\end{tabular}

The influence of the hydro-technical constructions situated in Upper and Middle Danube has inevitably led to a significant diminishing of the sediment flow in Low Danube. The registered average sediment discharge for 1961-1970 at Svishtov Hydrometric Station $(554.3 \mathrm{~km})$ is $1,664 \mathrm{~kg} / \mathrm{s}\left(52.475 \times 10^{6} \mathrm{t} / \mathrm{an}\right)$. For the same period average annual tendency is observed to decrease the registered sediment discharge with $11.44 \mathrm{~kg} / \mathrm{s}$ (Table 1). The average annual sediment discharge before Iron Gates construction, according to Bondar [1], is $57.9 \times 10^{6}$ t/an.

Looking at the multi-annual aspect in the period between the two barrages Iron Gates I and II construction (1971-1983) the average annual sediment runoff of the Danube River at Svishtov Hydrometric Station has diminished with $39 \%$ compared to the period 1961-1970 (Table 1). The most significant decrease of the sediment runoff $(61 \%)$ is observed during the first year after the Iron Gate I completion (1971) compared to the previous 1970 (Fig. 2). The reduction of the suspended load in 1971 compared to the previous year reaches $18.8 \times 10^{6} \mathrm{t}$ at Svishtov Hydrometric Station.

The period after the construction of the second barrage-Iron Gate II (1984-1995) coincides with the time of big droughts in the whole Balkan region. The impact of the both factors in this period has led to considerable decrease of the average annual sediment runoff (62\%) in Danube compared to the 1961-1970. In this period the biggest annual decrease of the sediment runoff has been registered with $45.3 \mathrm{~kg} / \mathrm{s}$.

During the last period (1996-2008) some insignificant restoration of the average annual sediment runoff has been noticed after the period of droughts but the decrease of the multi-annual sediment discharge continues to be very big at about $72 \%$ compared to the first period (1961-1970). The construction of the Iron Gates I and II has led to very significant and constant reduction of the sediment runoff in low Danube as it is demonstrated using the data at Svishtov Hydrometric Station $(554.3 \mathrm{~km})$. The retention capability of the both reservoirs for 1971-2008 reaches $72 \%$.

Studying the inter-annual aspect the reduction of the average monthly sediment discharge in the last 12 years period (1996-2008) compared to the period before Iron Gates construction (1961-1970) is in the frame of $44 \%-84 \%$ at Svishtov Hydrometric Station $(554.3 \mathrm{~km})$ shown in Fig. 3.

\subsection{Turbidity and Grain Size Distribution of Suspended Sediments}

To determine the turbidity of Danube water at Svishtov Hydrometric Station $(554.3 \mathrm{~km})$ eleven regular daily samplings have been done using a bathometer with a changeable depth from 0.5 till 1.5 $\mathrm{m}$ at the river profile. The average annual turbidity of the Danube at Svishtov Hydrometric Station before Iron Gates construction varied between 176 and 330 $\mathrm{g} / \mathrm{m}^{3}$ with an average multi-annual value of 238.5 $\mathrm{g} / \mathrm{m}^{3}$ for $1961-1970$.

In the last 12 years (1996-2008) the alteration of the average annual turbidity is in the frame of 35.4-147.6 $\mathrm{g} / \mathrm{m}^{3}$ with an average multi-annual value of $85.5 \mathrm{~g} / \mathrm{m}^{3}$.

As a result of the strong impact of the Iron Gates I and II a significant change in the inter-annual distribution of the turbidity has been observed expressed as a considerable equalization of the distribution with decreased maximum values (Fig. 4).

Discrepancy between the transportation capacity of the Danube mainstream and the decreased sediment 
content after the Iron Gates construction creates conditions for a river bed erosion. After 2000 a big increase of the minimal monthly turbidity has been observed at Svishtov Hydrometric Station $(554.3 \mathrm{~km})$ in Fig. 5. Similar increase of the absolute minimal turbidity has been noticed as well after the completion of Iron Gate I as a result of river bed erosion processes [3].

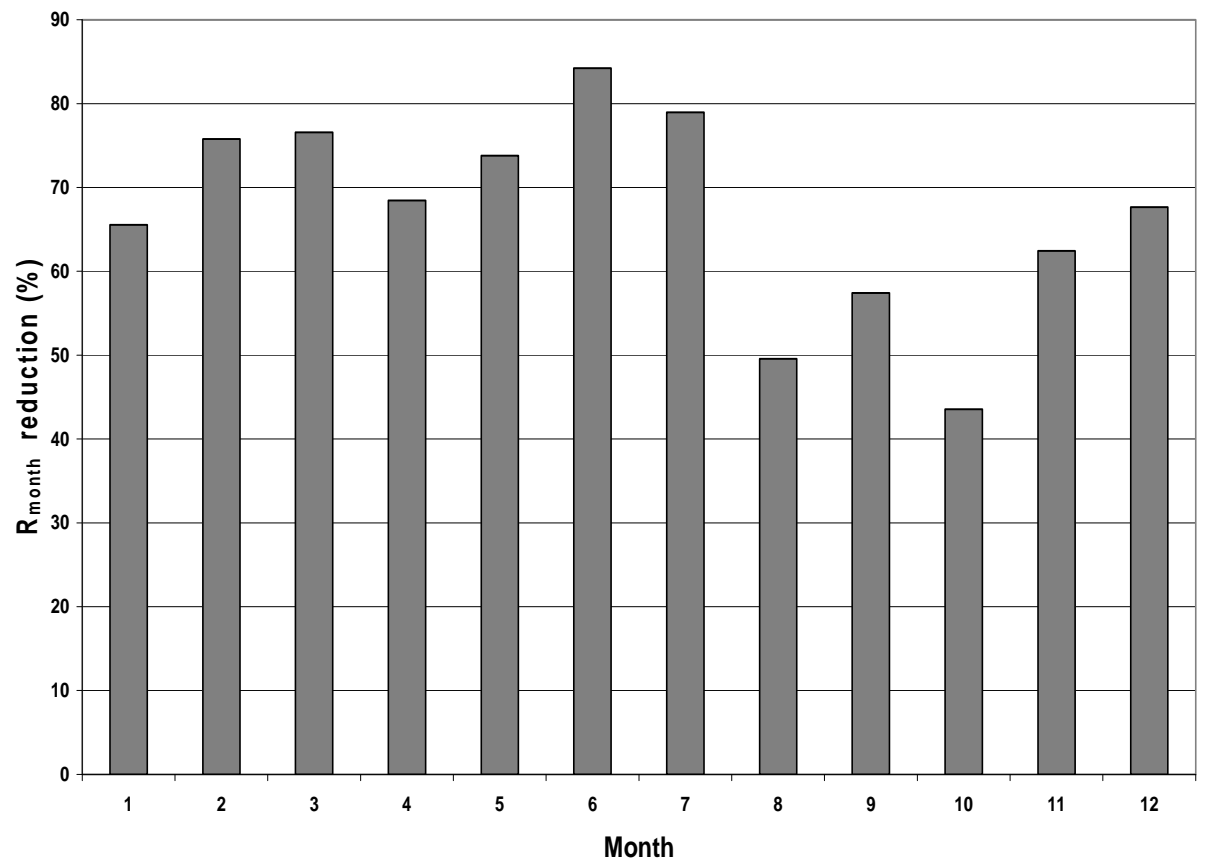

Fig. 3 Reduction of the average monthly sediment discharge for 1961-1970 at Svishtov Hydrometric Station (554.3 km), in period: 1961-1970.

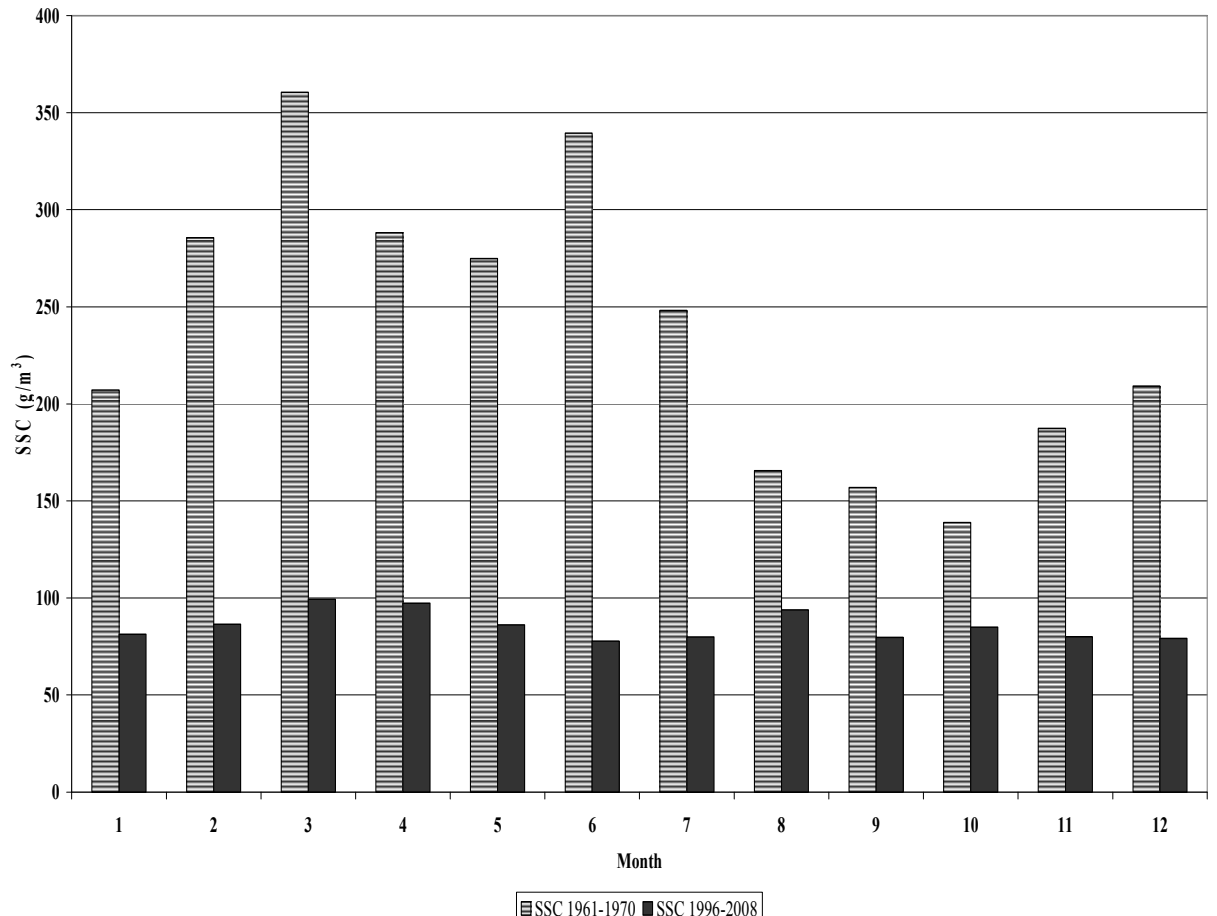

Fig. 4 Inter-annual distribution of the turbidity at Svishtov Hydrometric Station $(554.3 \mathrm{~km})$, in periods: $1961-1970$ and 1996-2008. 


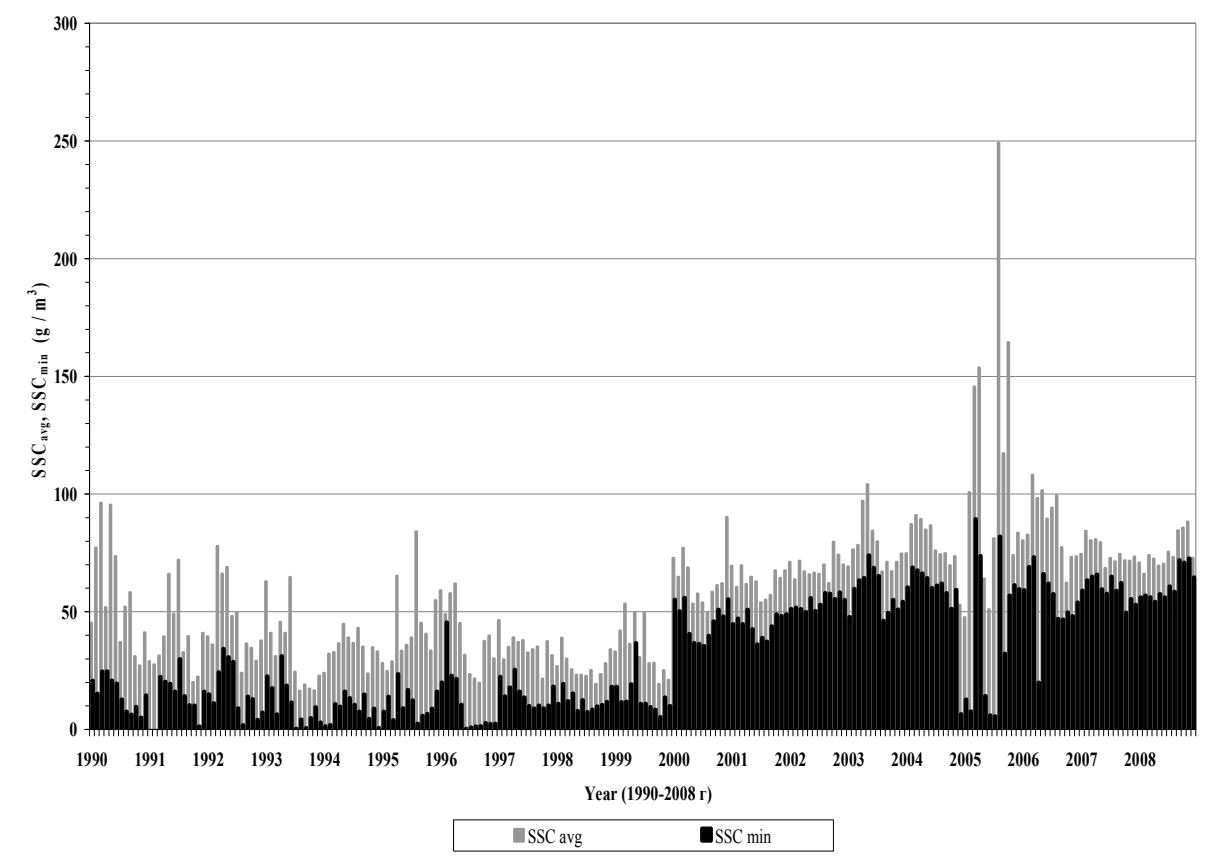

Fig. 5 Average and minimal monthly turbidity values at Svishtov Hydrometric Station (554.3 km), in period: 1990-2008.

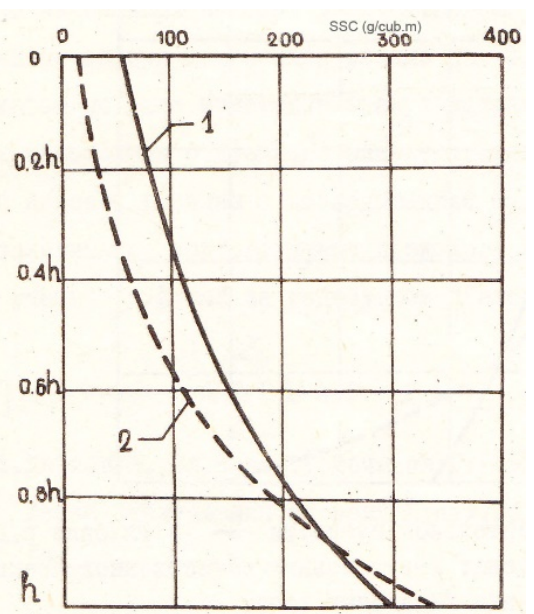

Fig. 6 Change of the turbidity at Novo selo $(833.6 \mathrm{~km})$ after Petchinov [2].

1: before Iron Gate construction;

2: after Iron Gate construction.

After the Iron Gate construction lowering of the Danube bed has been observed along the Bulgarian sector with lowering of the erosion basis of the tributaries whose estuaries constantly became deeper [4].

Development of the erosion processes breeds a new configuration of the turbidity distribution considering the cross-section profiles [2]. According to the author some increase of the turbidity gradient has been observed in the depth as result of change in the granulometric content of suspended sediments as shown in Fig. 6.

Systematic measurements of the granulometric content of the suspended sediments are missing for the Bulgarian sector of Danube. There are some sporadic investigations but the using of different techniques and methods makes the comparisons very difficult. Anyway according to the existing studies the prevailing size of suspended sediments in the Bulgarian sector is under $0.05 \mathrm{~mm}$. The smallest particles are distributed almost equally from the surface to the bottom while he bigger ones increase going to the bottom - at Svishtov Hydrometric Station $(554.3 \mathrm{~km})$ from $20 \%$ till $50 \%[2,5]$.

Ratios between small and big fractions change from point to point on the one hand and in the frame of the same point on the other depend on the hydrodynamic characteristics of the river stream. Some data as result of sporadic measurements are presented in Table 2 [1]. 
Table 2 Granulometric content of the suspended sediments in Bulgarian Danube Sector (\%).

\begin{tabular}{|c|c|c|c|c|c|c|c|c|c|}
\hline \multirow{2}{*}{ Point } & \multirow{2}{*}{$\begin{array}{l}\text { Data of } \\
\text { measurement }\end{array}$} & \multirow{2}{*}{$\begin{array}{c}\text { Turbidity } \\
\left(\mathrm{g} / \mathrm{m}^{3}\right)\end{array}$} & \multicolumn{7}{|c|}{ Diameter of particles $(\mathrm{mm})$} \\
\hline & & & $1-0.5$ & $0.5-0.25$ & $0.25-0.1$ & $0.1-0.05$ & $0.05-0.01$ & $0.01-0.002$ & $<0.002$ \\
\hline $\mathrm{km} 500$ & VI. 1960 & 550 & 0.0 & 0.4 & 2.3 & 10.5 & 30.1 & 36.0 & 20.7 \\
\hline km 523 & VI. 1960 & 300 & 0.0 & 0.0 & 0.3 & 3.5 & 20.2 & 36.1 & 39.9 \\
\hline Russe & 1.X. 1965 & - & - & - & 6.7 & 7.6 & 51.0 & 34.7 & \\
\hline Svishtov & 14.V. 1964 & - & 0.2 & 2.1 & 15.2 & 25.5 & \multicolumn{3}{|c|}{ under $0.05 \mathrm{~mm} ; 57.0 \%$} \\
\hline Svishtov & 14.VII. 1964 & - & 0.0 & 3.1 & 12.0 & 27.0 & \multicolumn{3}{|c|}{ under $0.05 \mathrm{~mm} ; 57.9 \%$} \\
\hline Svishtov & 9.VI. 1965 & 180 & 0.5 & 10.1 & 9.6 & 17.2 & 32.3 & 14.1 & 16.2 \\
\hline Novo selo & 22.V. 1965 & 223 & 1.2 & 11.9 & 12.7 & 13.5 & 22.0 & 17.4 & 21.3 \\
\hline Novo selo & 23.V. 1965 & 163 & - & 13.8 & 7.2 & 15.5 & 19.9 & 16.3 & 27.3 \\
\hline Novo selo & 20.VI. 1965 & 93 & 4.0 & 16.0 & 17.0 & 18.0 & 23.0 & 10.0 & 12.0 \\
\hline Novo selo & 21.VI. 1965 & 116 & 2.0 & 11.0 & 20.0 & 22.0 & 18.0 & 10.0 & 17.0 \\
\hline Novo selo & 23.VI. 1965 & 155 & 4.0 & 17.0 & 18.0 & 17.0 & 16.0 & 10.0 & 18.0 \\
\hline
\end{tabular}

\section{Conclusions}

The influence of the hydro-technical constructions in the upper and lower Danube stream has led to decrease of the sediment content in the low Danube stream. The construction of Iron Gates I and II has significantly reduced the sediment runoff including at Svishtov Hydrometric Station $(554.3 \mathrm{~km})$ near the Belene nuclear power station platform.

The decreased average annual sediment discharge reaches at $72 \%$. Except a considerable decrease of the sediment runoff at the studied Danube Stretch there is a significant alteration of the inter-annual turbidity distribution, equalization of this distribution with diminished maximum values.

All these constant changes into the sediment runoff and turbidity distribution could be assessed as favorable with a view to the technical water supply of the Belene nuclear power station but unfavorable regarding the river bed stability along the power station platform.

\section{References}

[1] Bondar, C., State, I., Cernea, D., and Harabagiu, E. 1991. "Water Flow and Sediment Transport of the Danube at Its Outlet into the Black Sea." Journal of Meteorology and Hydrology 21 (1): 21-5.

[2] Technika, 1977. Hydrological Reference Book on the Danube River.

[3] Rajnov, S., Ninov, I., Petchinov, D., and Gergov, G. 1981. "Suspended Sediments in Bulgarian-Romanian Sector of Danube." In Collected Materials of Bulgarian Academy of Sciences, pp. 185-228.

[4] Petchinov, D. 1982. "Alteration of the Particle Size Distribution as Result of Iron Gate I." In Proceedings of the 7th Conference of Danubian Countries on Hydrological Forecasts, Bucharest, pp. 3-17. (in Russian).

[5] Gergov, G. 2001. Hydrological Studies, Chapter II River Sediments. Bulgarian National Water Association, 84-202. 